\title{
Achievement goal orientations, sport motivation and competitive performance in beach volleyball players
}

\author{
Michaela Knoblochova ${ }^{\bowtie}$, Jiri Mudrak, and Pavel Slepicka \\ Faculty of Physical Education and Sport, Charles University, Prague, Czech Republic
}

\begin{abstract}
Background: From the perspective of achievement goal orientation theory, athletes may evaluate their performance by comparing current achievements with previous achievements (task orientation) or with those of other athletes (ego orientation); these two orientations may affect their sport motivation and performance outcomes in different ways. Objective: Based on a sample of competitive Czech beach volleyball players, this study aimed to assess the relationships among achievement goal orientations (task/ego), sport motivation (represented by intrinsic motivation, extrinsic regulation, and amotivation), and athletes' competitive performance. Methods: A total of 128 beach volleyball players (63 men and 65 women, age $26 \pm 6.27$ years, range 14-42 years) from the highest Czech national competition participated in the questionnaire survey. The questionnaire battery included the Sport Motivation Scale- 6 as a measure of self-determined sport motivation and the Perception of Success Questionnaire as a measure of achievement goal orientation. We used multiple linear regression models to assess the relationships among achievement goal orientations, different types of sports motivation, and athletes' performance in sports competition measured by their point averages at the end of the season. Results: In regression models, we observed different effects of task and ego orientations on dependent variables, including intrinsic motivation, external regulation and athletes' competitive performance. Specifically, we found a highly significant effect of task orientation in the model of intrinsic motivation $\left(B=.522, p<.001, R^{2}=.255\right.$ ) and a highly significant effect of ego orientation in the model of external regulation $\left(B=.394, p<.001, R^{2}=.132\right.$ ). Furthermore, we found a significant effect of ego orientation in the model of athletes' competitive performance $\left(B=.239, p=.005, R^{2}=.122\right)$. Conclusions: We assume that task and ego orientations contribute to different outcomes in competitive athletes, with task orientation supporting athletes' interest in and enjoyment of the sport and ego orientation supporting athletes' external regulation and performance in competition. Based on self-determination theory, task orientation may affect intrinsic motivation through the satisfaction of the basic needs of autonomy, relatedness and competence. At the same time, ego orientation may support less self-determined motivation but may also represent an advantage in the highly competitive environment of elite sports.
\end{abstract}

Keywords: task orientation, ego orientation, self-determination theory, intrinsic motivation, external regulation, performance, competition, sport psychology

\section{Introduction}

Competitive sports with a dominant focus on performance represent an optimal context for the study of achievement motivation. To reach a high level of performance, athletes need to develop motivational characteristics that support their commitment to the sport, facilitate long-term effort and assist in coping with difficulties (Baker \& Young, 2014; Côte et al., 2003; Helsen et al., 1998; Vallerand \& Miquelon, 2007). On the other hand, highly motivated athletes with maladaptive beliefs, including excessive perfectionism or whatever it takes ethics, may experience negative consequences, including burnout, conflicts, cheating, health problems or dropping out from the sport (Boiché \& Sarrazin, 2009; Calvo et al., 2010; Fraser-Thomas et al., 2008; Gustafsson et al., 2017; Lemyre et al., 2008; Mudrak et al., 2018; van de Pol \& Kavussanu, 2012;
Waldron \& Krane, 2005). Extant research suggests that these two motivational paths may be partially explained by the types of goals athletes tend to pursue, that is, by their achievement goal orientations (Kavussanu \& Roberts, 2001; Roberts et al., 1998).

In general, athletes who orient their achievement goals towards their self-development and evaluate their results on the basis of comparisons with a previous level of their own performance (task or mastery orientation) tend to experience more positive outcomes than athletes who focus on winning and evaluate their performance based on comparison with the results of other people (ego or performance orientation). These contradictory effects of task and ego orientations have been evidenced, for example, in cheating during sports competition (Ring \& Kavussanu, 2018), athletes' prosocial judgment (Sage et al., 2006), antisocial behavior towards opponents (Boardley \& Kavussanu,

$\triangle$ Corresponding author: Michaela Knoblochova, e-mail knoblochova.misa@gmail.com, ORCID® record https://orcid.org/0000-0001-8851-4441

Article history: Received January 13 2021, Accepted July 16 2021, Published August 232021

Copyright: @ 2021 The Author(s). Published by Palacký University Olomouc. This is an open access article distributed under the terms of the Creative Commons Attribution License (https://creativecommons.org/licenses/by/4.0/), which permits unrestricted use, distribution, and reproduction in any medium, provided the original author and source are credited. This license does not cover any third-party material that may appear with permission in the article. 
2010), sportspersonship and instrumental aggression (Yukhymenko-Lescroart, 2018), or athletes' psychological well-being and social connectedness (Wayment \& Walters, 2017). Biddle et al. (2003) suggested a more balanced perspective in a systematic review relating task orientation in athletes to numerous positive outcomes, including perceptions of competence, positive emotions and lower negative emotions, and relating ego orientation in athletes to both positive outcomes, such as competence beliefs, and negative outcomes, such as unsportsmanlike attitudes or aggressive behavior.

Regarding important psychological outcomes, task and ego orientations have been found to predict different dimensions of sports motivation (Duda, 2013; Mudrak et al., 2018; Texeira et al., 2020; Tomczak et al., 2020a, $2020 \mathrm{~b}$ ). The conceptualization of sports motivation stemming from self-determination theory (Mallet et al., 2007; Mudrak et al., 2018; Ryan \& Deci, 2000; Vallerand \& Losier, 1999) suggests that self-determined motivation based on interest and enjoyment (intrinsic motivation) and identity (integrated regulation) or focused on self-development (identified regulation) is positively associated with a number of positive consequences in athletes, including effort; engagement; and lower incidence of stress, burnout, risk behavior, or drop-out. The opposite relationships have been found on the other end of this self-determination continuum when athletes engage in sport activity to maintain a sense of self-worth (introjected regulation), meet expectations of other people and gain external incentives (external regulation), or perceive a lack of control over the activity (amotivation). From the self-determination theory perspective, different reasons that people engage in achievement behavior stem from how the activity satisfies three basic human needs: a need for competence, relatedness and autonomy (Ryan \& Deci, 2000).

Duda (2013) provides an argument for the integration of achievement goal orientation theory and self-determination theory in the sports context, suggesting that a positive empowering motivational climate "strengthens the focus on the task, promotes autonomy and provides social support" (Duda, 2013, p. 314), while a disempowering motivational climate promotes values and practices that are "controlling and ego-focused" (Duda 2013, p. 314). Other studies suggest a hierarchical relationship between achievement goal orientations and sport motivation (Duda et al., 1995; Ntoumanis, 2001; Mudrak et al., 2018; Ryan \& Deci, 2000; Standage et al., 2003; Texeira et al., 2020; Tomczak et al., 2020a, 2020b). In this way, task and ego goal orientations represent different interpretative frameworks that influence the ways in which athletes perceive their autonomy, competence and relatedness to others and affect the degree to which the athletes perceive themselves as self-determined (Duda et al., 1995; Ntoumanis, 2001; Standage et al., 2003). For example, Mudrak et al. (2018) found that ego orientation predicted external regulation and amotivation, whereas task orientation predicted intrinsic motivation and lower amotivation in adolescent competitive athletes. Duda et al. (1995) provided evidence that task orientation (as opposed to ego orientation) predicted sports-related intrinsic motivation in youth athletes. Tomczak et al. (2020a, 2020b) found that task orientation was significantly related to more self-determined dimensions of sport motivation and lower amotivation, whereas ego orientation was related to less self-determined dimensions of sport motivation.

While there is strong evidence regarding the relationships between achievement goal orientations and sport motivation, less research attention has been given to the relationships between different achievement goal orientations and actual performance. Several studies conducted within noncompetitive contexts of leisure sports (King \& Williams, 1997; Palmer et al., 2017) or within youth competitive sports (Van-Yperen \& Duda, 1999) suggest that task/mastery orientation improves motor learning; even adult elite athletes subjectively preferred mastery over performance goals (Pensgaard \& Roberts, 2002). Harackiewitz and Barron (2000) showed that both achievement goal orientation types may affect different aspects of performance. In a series of laboratory experiments, task-oriented students reported higher engagement, but ego-oriented students achieved better results in simulated experimental tasks. These authors suggest that ego orientation might be more beneficial in competition-oriented environments with limited opportunities to succeed, while the importance of task orientation would increase in less competitive environments (Harackiewitz \& Barron, 2000).

There is some evidence for this conclusion in the sportrelated context, as van de Pol et al. (2012) showed in an experiment involving golf putting as an objective measure of motor performance. In this experiment, ego orientation predicted performance in a competitive condition in which athletes competed against each other, as opposed to a training condition in which participants were urged to focus on their own skill development. Some studies also suggest that athletes show higher ego orientation in competition and higher task orientation in training (van de Pol \& Kavussanu, 2011). However, there appears to be a lack of studies exploring relationships between achievement goal orientations and objective performance, especially considering the large number of studies that relate achievement goal orientations to subjective outcomes.

On this basis, in this study, we aim to explore diverse relationships among task and ego orientations, sport motivation, and sport performance in the context of competitive beach volleyball. Based on the reviewed research (e.g., Duda et al., 1995; Ntoumanis, 2001; Mudrak et al., 2018; Texeira et al., 2020; Tomczak et al., 2020a, 2020b), we hypothesized that task orientation would be positively related to a more self-determined form of motivation (i.e., intrinsic motivation) and negatively related to less selfdetermined forms of motivation (i.e., extrinsic regulation and amotivation); we expected the opposite direction of relationships for ego orientation. In addition, given the highly competitive context in which these athletes perform, we expected that ego orientation may be a significant predictor of their competitive performance (Harackiewitz \& Baron, 2000; van de Pol et al., 2012). 


\section{Methods}

\section{Procedures}

The article presents the results of a questionnaire survey conducted in 2016. The data were collected by the first author at beach volleyball tournaments in the highest Czech national competition that took place during the 2016 competitive season, between May and September. Before data collection began, the research was approved by the Ethics Committee of the Faculty of Physical Education and Sport, Charles University. The data collection was voluntary and anonymous, and the questionnaire was constructed in a way that prevented the identification of individual participants or their clubs. Prior the data collection, the athletes signed an informed consent of participation.

\section{Participants}

The research sample consisted of 128 beach volleyball players playing at the highest level of competition of the Czech Beach Volleyball Association. The sample included 63 mens and 65 women. The average age of the respondents was $26 \pm 6.27$ years, ranging between 14 ando 42 years. The inclusion criteria for the participants were that at the time of the data collection, they had to have acquired points in the Czech Beach Volleyball Association rankings. A total of 134 players, 67 men and 67 women, were contacted, and 4 men and 2 women did not complete the questionnaire. Therefore, the response rate was $95.5 \%$.

\section{Measurement}

The questionnaire battery used in the study consisted of two parts: achievement goal orientation and sport motivation. Achievement goal orientation was measured by the Perception of Success Questionnaire (PSQ; Roberts et al., 1998), and sport motivation was measured by the Sport Motivation Scale-6 (SMS-6; Mallett et al., 2007). The instruments have not been standardized in the Czech context; they were translated for the purpose of this research from the original English versions by a standard back-translation procedure (Del Greco et al., 1987). We also estimated the objective performance of the participants as average points achieved per tournament during the season; objective performance was calculated as the ratio of points acquired and the number of tournaments played by the participant.

\section{PSQ}

The PSQ measures achievement goal orientation, that is, which types of sport-related outcomes are perceived as success by the respondents. The PSQ is based on a two-dimensional approach to achievement goal orientation and distinguishes between success stemming from mastering a task (task) and success in comparison with others (ego). Respondents indicate on a 5-point Likert scale ranging from 1 (strongly disagree) to 5 (strongly agree) the sports situation in which they perceive themselves to be most successful. An example of a task item is "When playing a sport, I feel most successful when I truly improve," and an example of an ego item is "When playing a sport, I feel most successful when I am the best." The task and ego dimensions are computed as the means of all corresponding items (Roberts et al., 1998). In the original version, the PSQ consisted of twelve items, six in each dimension. To increase the reliability of the subscales, we conducted exploratory factor analysis of the full scale, based on which we excluded one item showing the lowest factor loading from each dimension (i.e., "I try hard" from the task dimension and "I accomplish something others cannot do" from the ego dimension). The resulting 10 -item version of the PSQ showed good reliability in our study, as well as in the full scale (Cronbach's $\alpha=.734$ ), task (Cronbach's $\alpha=.852$ ) and ego (Cronbach's $\alpha=.809$ ) dimensions.

\section{SMS-6}

To examine the reasons respondents participate in sports, we implemented several constructs based on self-determination theory (Mallett et al., 2007). Specifically, we used the dimensions of intrinsic motivation, external regulation, and amotivation from the SMS-6 (Mallett et al., 2007). Each of these dimensions was measured by four items on a 5 -point Likert scale ranging from 1 (Does not correspond at all) to 5 (Corresponds completely). Respondents were prompted by the statement, "Using the scale below, please indicate to what extent each of the following items corresponds to one of the reasons for which you are presently practicing your sport", based on which the respondents indicated their reasons for their participation in sports. The items used to measure each dimension included "For the pleasure of discovering new performance strategies" (intrinsic motivation), "Because it allows me to be well regarded by people I know" (external regulation), and "I don't know anymore; I have the impression of being incapable of succeeding in this sport" (amotivation). The SMS-6 has been widely used in sports psychology research and has shown good psychometric properties (Mallett et al., 2007). In our study, the SMS-6 as a whole (Cronbach's $\alpha=.790$ ), as well as the dimensions of amotivation (Cronbach's $\alpha=.762$ ) and external regulation (Cronbach's $\alpha=.773$ ), showed good reliability. However, the dimension of intrinsic motivation showed unsatisfactory reliability in our sample (Cronbach's $\alpha=.638$ ). Therefore, we excluded the least fitting item (i.e., "For the excitement I feel when I am deeply involved in the activity") from the scale, which resulted in acceptable reliability of the shortened scale (Cronbach's $\alpha=.773$ ).

\section{Statistical analysis}

We analyzed the cross-sectional questionnaire data in the statistical software SPSS (Version 23 for Windows; IBM, Armonk, NY, USA), in which we computed the descriptive statistics, correlations, and four multiple regression models. The models included PSQ subscales of task and ego as predictors and included SMS-6 subscales of intrinsic motivation, external regulation, and amotivation, as well as competitive performance measured by the point averages as dependent variables. Prior to the analyses, we examined the distribution of our data, which did not show a normal distribution, as the Shapiro-Wilk test outcomes were significant $(p<.001)$ for all included variables. Upon inspection, the point averages approximated a log-normal distribution. Therefore, we log-transformed the data, which resulted in a normal distribution of the log-transformed data, as 
evidenced by a nonsignificant Shapiro-Wilk test outcome $(p=.412)$.

Considering the nonnormal distribution of our data, we computed nonparametric Spearman's rank-order correlations. Regarding the regression models, the nonnormal distribution of the included variables did not present a limitation, as only errors represented by the residuals of the regression models needed to be normally distributed in linear regression (Williams et al., 2013). Three of our four hypothesized models met this assumption, including the model of competitive performance (Shapiro-Wilk test $p=.919$ ), intrinsic motivation (Shapiro-Wilk test $p=.464$ ), and external regulation (Shapiro-Wilk test $p=.129)$. The amotivation model did not meet the assumption of normally distributed residuals; therefore, we excluded the model from further analysis. As we included only data from complete questionnaires, there were no missing values. We did not identify any outliers in the data. All the reported regression coefficients from our analyses were standardized. We interpreted the results at the 5\% level of significance.

\section{Results}

First, descriptive statistics and correlations are presented in Table 1. On average, our respondents reported higher task orientation $(4.40 \pm 0.64)$ than ego orientation $(3.35 \pm 0.80)$, which is similar to the results of other studies (see Table 2). On the motivational continuum, our respondents reported the highest level of intrinsic motivation $(3.37 \pm 0.80)$, followed by extrinsic regulation $(2.13 \pm 0.83)$ and amotivation $(1.15 \pm 0.73)$. The participants showed fairly large variability regarding performance outcomes, as they scored an average of 27.69 points per tournament with a standard deviation of 19.97.

Correlation analysis revealed several significant relationships. On average, task orientation was negatively related to age $\left(r_{s}=-.317, p<.001\right)$. Regarding the correlations between motivational constructs, we found positive significant relationships between task orientation and intrinsic motivation $\left(r_{\mathrm{s}}=.456, p<.001\right)$ and a negative relationship between task orientation and amotivation $\left(r_{s}=-.272\right.$, $p=.002$ ). Furthermore, we observed significant relationships between ego orientation and external regulation $\left(r_{s}=.368, p<.001\right)$ and between ego orientation and competitive performance measured by average points per tournament $\left(r_{\mathrm{s}}=.228, p=.010\right)$.

In Table 3, three multiple regression models are presented in which achievement goal orientation predicted different types of sport motivation and competitive performance represented by point averages. As we hypothesized, the results of these models suggest that task and ego

Table 1 Descriptive statistics and Spearman correlations

\begin{tabular}{|c|c|c|c|c|c|c|c|c|}
\hline Variable & $M$ & $S D$ & 1 & 2 & 3 & 4 & 5 & 6 \\
\hline 1. Age & 25.93 & 6.27 & - & & & & & \\
\hline 2. Ego orientation & 3.348 & 0.803 & -.100 & - & & & & \\
\hline 3. Task orientation & 4.401 & 0.637 & $-.317^{* *}$ & .062 & - & & & \\
\hline 4. Intrinsic motivation & 3.372 & 0.803 & -.108 & .076 & $.456 * *$ & - & & \\
\hline 5. External regulation & 2.131 & 0.826 & -.083 & $.368^{* *}$ & -.087 & -.073 & - & \\
\hline 6. Amotivation & 1.153 & 0.731 & .112 & -.078 & $-.272^{*}$ & -.111 & .124 & - \\
\hline 7. Average points per tournament & 27.690 & 19.968 & $.207^{*}$ & $.228 * *$ & .065 & -.012 & $.208^{*}$ & .008 \\
\hline
\end{tabular}

${ }^{*} p \leq .05,{ }^{* *} p \leq .01$.

Table 2 Comparing the Perception of Success Questionnaire measures of task and ego orientations in other samples (as $M \pm S D$ )

\begin{tabular}{lcccc}
\hline & Current study & Lochbaum et al. (2017) & Mudrak et al. (2018) & Tomczak et al. (2020b) \\
$N=128$ & $N=5679$ & $N=1035$ & $N=412$ \\
\hline Achievement goal orientation & $N=128.348 \pm 0.803$ & $3.350^{\mathrm{a}}$ & $3.660 \pm 0.800$ & $3.670 \pm 0.940$ \\
Task orientation & $4.401 \pm 0.637$ & $4.260^{\mathrm{a}}$ & $4.330 \pm 0.600$ & $4.730 \pm 0.570$ \\
\hline
\end{tabular}

astandard deviations were not reported.

Table 3 Task and ego orientations as predictors of sport motivation and competition outcomes

\begin{tabular}{|c|c|c|c|c|c|c|}
\hline \multirow[b]{2}{*}{ Predictor variable } & \multicolumn{2}{|c|}{ Model 1: Intrinsic motivation ${ }^{a}$} & \multicolumn{2}{|c|}{ Model 2: External regulation ${ }^{b}$} & \multicolumn{2}{|c|}{ Model 3: Competitive performance } \\
\hline & B & $p$ & ß & $p$ & ß & $p$ \\
\hline Sex & -.062 & .431 & .057 & .505 & $-.193^{*}$ & .026 \\
\hline Age & .023 & .783 & -.031 & .734 & $.290^{* *}$ & .002 \\
\hline Ego orientation & .022 & .773 & $.394 * * *$ & .000 & $.239 * *$ & .005 \\
\hline Task orientation & $.522 * * *$ & $<.001$ & -.063 & .480 & .066 & .459 \\
\hline$R^{2}$ & .255 & & .132 & & .122 & \\
\hline
\end{tabular}

Note. Sex was coded as $1=$ woman and $2=$ man. ${ }^{\mathrm{a}} F(4,123)=11.890, p<.001 .{ }^{b} F(4,123)=5.819, p<.001 .{ }^{c} F(4,123)=5.405, p<.001$. Statistical significance of correlations: ${ }^{*} p \leq .05,{ }^{* *} p \leq .01,{ }^{* * *} p \leq .001$. 
achievement goal orientations are related to different aspects of sport performance. Specifically, in model 1, we found that task orientation but not ego orientation predicted intrinsic motivation $\left(\beta=.522, p<.001, R^{2}=.255\right)$. In model 2 , we found that ego orientation but not task orientation predicted external regulation $(B=.394, p<.001$, $\left.R^{2}=.132\right)$. In model 3 , ego orientation significantly predicted better competitive performance $(\beta=.239, p=.005$, $R^{2}=.122$ ), even when controlling for age and sex, which also had significant effects in the model.

\section{Discussion}

These results mostly support our hypotheses about the relationships between achievement goal orientation, sport motivation and competition outcomes. Task orientation was positively related to higher intrinsic motivation, while ego orientation was positively related to external regulation and competitive performance. In other words, athletes more focused on self-development (i.e., task-oriented athletes) also more frequently participated in their sport because they enjoyed it, and athletes who were more focused on comparison with others (i.e., ego-oriented athletes) participated in sport more to fulfill social expectations and achieved better results. At the same time, we did not confirm all our hypotheses regarding the negative relationships between achievement goal orientation and sport motivation. Task-oriented athletes were not necessarily less extrinsically motivated, and ego-oriented athletes did not enjoy their sport less. In this way, we may argue that both achievement goal orientations relate to different aspects of sport participation through relatively independent paths, which is further supported by the fact that both dimensions of achievement goal orientation were uncorrelated in our sample.

Along with the findings of Duda et al. (1995), we may explain the positive effects of task orientation observed in our study and other studies as resulting from several processes. First, higher task orientation may reduce the probability that athletes would perceive themselves as incompetent because they compare themselves with self-referenced standards of achievement rather than standards set by other athletes, some of whom would inevitably perform at a higher level. Similarly, as other authors have argued, task-oriented athletes experience fewer social constraints on their autonomy because they do not feel judged and obliged to meet the performance standards set by other people. Additionally, task-oriented athletes may experience better relationships because they do not perceive themselves to be in competition with others and do not compete for limited resources determined by achieving victory (Duda et al., 1995; Ntoumanis, 2001; Standage et al., 2003).

Notably, task orientation did not have significant effects on athlete performance in our sample. One of the possible explanations for this outcome may be that almost all of our participants were more or less task oriented as participants were often classified as having task orientation and, in comparison to ego orientation, the variability of task orientation was lower in our sample. Therefore, we might speculate that a high level of task orientation is important to reach a level at which participants qualify for competition but not for competitive performance. This is supported by the results of other studies; for example, van de Pol et al. (2012) found that task orientation was related to effort in training conditions but not to performance in the conditions of competition. Furthermore, the age and level of our participants might have played a role in the present findings, as positive effects of task orientation on motor performance have been observed in youth athletes or in noncompetitive settings (King \& Williams, 1997; Palmer et al., 2017; VanYperen \& Duda, 1999), while our sample mostly consisted of highly competitive adult athletes.

The present study and other available studies show almost unequivocally positive effects of task orientation, but the picture is less clear with regard to the effects of ego orientation, as the effects of ego orientation are frequently related to controlled forms of motivation (e.g., Lochbaum et al., 2016; Mudrak et al., 2018; Tomczak et al., 20 2020b; Vasconcellos et al., 2020). Our results also suggest that ego orientation significantly relates to external regulation, which has been generally considered a less optimal form of motivation related to some negative psychological outcomes (Deci \& Ryan, 2000; Roberts et al., 2018). Within the self-determination theory framework, we may again argue that the relationship between ego orientation and external regulation may be due to the effects of ego orientation on the satisfaction of the basic needs of autonomy, competence and relatedness. As ego-oriented individuals perceive themselves more in competition with others, they may also experience worse relationships, higher constraints on their autonomy and worse learning opportunities. This may be because their participation and outcomes of the activity depend on the behavior and results of other people, and the feedback obtained on winning/losing may be less conductive to further learning.

At the same time, some studies (Harackiewitz \& Barron, 2000; van de Pol \& Kavussanu, 2011), including our research, associated ego orientation with better competitive performance. It appears that the nature of this relationship may be moderated by other motivational variables, such as whether people are involved in the task, perceive themselves as sufficiently competent (Harackiewitz \& Barron, 2000), or focus on achieving success versus avoiding failure (van Mierlo \& van Hooft, 2020). In this way, our sample of high-level beach volleyball players generally represented a group of involved athletes operating in a highly competitive context in which ego orientation might represent a competitive advantage. Considering the competitive level of our participants, it appears that the participants in the present study mastered their sport at a sufficiently high level at which the motivational focus on ego-oriented goals provided an additional benefit for performance (van de Pol et al., 2012). Some studies also associated ego orientation with higher acceptance of unsportsmanlike behavior (Kavussanu \& Roberts, 2001), cheating (Ring \& Kavussanu, 2018) or instrumental aggression (Yukhymenko-Lescroart, 2018), which could possibly provide an advantage in high-level competition and facilitate competitive performance. 
These results have some implications for the development of athletes and coaching practices in competitive sports. It appears that both orientations may contribute to different outcomes, which should be taken into account by the coaches of competitive athletes. Considering our results as well as the results of other studies, we suggest that coaches should focus on developing a task-involving motivational climate to facilitate athletes' positive experience by following practices that emphasize cooperation and inclusiveness, reward effort and provide constructive noncontrolling feedback. At the same time, it appears that the ego orientation has important implications for performance in competitive adult athletes. This may be more important in the context of competition, where a focus on winning may constitute an advantage leading to enhanced competitive performance, rather than in training. At the same time, excessive focus on ego may represent a double-edged sword, as it also relates to less optimal psychological outcomes and should be complemented by a focus on task and mastery.

However, to better understand the possible effects of achievement goal orientations in sport contexts, more research is needed, ideally encompassing different sports, age groups and levels of athlete performance. We believe that future research should focus especially on the diverse effects of both achievement goal orientations on objective performance outcomes, as these effects appear to be relatively under-researched compared to subjective psychological outcomes. In addition, the long-term effects of both achievement goal orientations on multiple sport-related outcomes, including athletes' performance and well-being, should be examined further in longitudinal large-scale studies. Finally, qualitative studies could provide a better understanding of the actual practices that facilitate athlete development in both achievement goal orientations and of their effects in the contexts of training and competition.

Our study has some limitations that should be considered. First, the study employed a cross-sectional design that limits causal interpretations of the proposed relationships. We based our hypotheses on a review suggesting that the proposed direction of the relationships would be at least partially valid; however, it is necessary to acknowledge that these relationships may be bidirectional, and we must interpret our results with caution. Additionally, we included a relatively small number of respondents in the study. However, the population of competitive beach volleyball players from which we drew the sample is highly selective, and we believe that our sample represents this population fairly well. At the same time, we included participants encompassing a relatively wide age range, which might also present a limitation, especially when assessing relationships between motivational variables that may be different for different age groups. Finally, our model explained only a moderate portion of the variance in the included dependent variables. Therefore, other variables not included in our study may contribute equally or even more than the evaluated variables in an explanation of sport motivation and competitive performance in competitive athletes.

\section{Conclusions}

In conclusion, our study showed that ego and task achievement orientations in competitive athletes might be associated with different outcomes, including different types of sport motivation and competition results. Specifically, in our multiple regression models, task orientation predicted intrinsic motivation, and ego orientation predicted external regulation and competitive performance. In this way, we confirmed some of our hypotheses, which suggests that both achievement goal orientations may influence sport outcomes through different paths and that the effects of ego orientation may be especially diverse and dependent on the individual and social contexts of athletes. We suggest that coaches should consider these findings to develop positive motivational climates that are supportive of an optimal development of full athletic potential in competitive athletes. However, our respondents were to some extent oriented towards the ego, which probably helped them achieve better results in the competition.

\section{Acknowledgments}

This study was supported by Charles University (grants PROGRES Q19, GAUK 1088120, and SVV 260599).

\section{Conflict of interest}

The authors report no conflict of interest.

\section{References}

Baker, J., \& Young, B. (2014). 20 years later: Deliberate practice and the development of expertise in sport. International Review of Sport and Exercise Psychology, 7(1), 135-157. https://doi.org/10.1080/1750984X.2014.896024

Biddle, S., Wang, C. J., Kavussanu, M., \& Spray, C. (2003). Correlates of achievement goal orientations in physical activity: A systematic review of research. European Journal of Sport Science, 3(5), 1-20. https://doi. org/10.1080/17461390300073504

Boardley, I. D., \& Kavussanu, M. (2010). Effects of goal orientation and perceived value of toughness on antisocial behavior in soccer: The mediating role of moral disengagement. Journal of Sport and Exercise Psychology, 32(2), 176192. https://doi.org/10.1123/isep.32.2.176

Boiché, J. C., \& Sarrazin, P. G. (2009). Proximal and distal factors associated with dropout versus maintained participation in organized sport. Journal of Sports Science \& Medicine, 8(1), 9-16. https://www.jssm.org/issm-08-9.xml\%3EFulltext

Calvo, T. G., Cervelló, E., Jiménez, R., Iglesias, D., \& Murcia, J. A. M. (2010). Using self-determination theory to explain sport persistence and dropout in adolescent athletes. Spanish Journal of Psychology, 13(2), 677-684. https://doi. org/10.1017/S1138741600002341

Côté, J., Baker, J., \& Abernethy, B. (2003). From play to practice: A development framework for the acquisition of expertise in team sports. In J. L. Starkes \& K. A. Ericsson (Eds.), Expert performance in sports: Advances in research on sport expertise (pp. 89-113). Human Kinetics.

Deci, L. E., \& Ryan, M. R. (2000). The "what" and "why" of goal pursuit: Human needs and the self-determination of behavior. Psychological Inquiry, 11(4), 227-268. https://doi.org/10.1207/S15327965PLI1104 01

Del Greco, L., Walop, W., \& Eastridge, L. (1987). Questionnaire development: 3. Translation. CMAJ, 136(8), 817-818.

Duda, J. L. (2013). The conceptual and empirical foundations of Empowering Coaching $^{\mathrm{TM}}$ : Setting the stage for the PAPA project. International Journal of Sport and Exercise Psychology, 11(4), 311-318. https://doi.org/10.1080/16121 97X.2013.839414

Duda, J. L., Chi, L., Newton, M. L., Walling, M. D., \& Catley, D. (1995). Task and ego orientation and intrinsic motivation in sport. International Journal of Sport Psychology, 26(1), 40-63.

Fraser-Thomas, J., Côté, J., \& Deakin, J. (2008). Understanding dropout and prolonged engagement in adolescent competitive sport. Psychology of Sport and Exercise, 9(5), 645-662. https://doi.org/10.1016/i.psychsport.2007.08.003

Gustafsson, H., DeFreese, J. D., \& Madigan, D. J. (2017). Athlete burnout: Review and recommendations. Current Opinion in Psychology, 16, 109-113. https://doi. org/10.1016/j.copsyc. 2017.05.002 
Harackiewitz, J. M., \& Barron, K. E. (2000). Achievement goals and optimal motivation: A multiple goals approach. In C. Sansone \& J. M. Harackiewitz (Eds.) Intrinsic and extrinsic motivation (pp. 229-254). Academy Press. https://doi. org/10.1016/B978-012619070-0/50031-3

Helsen, W. F., Starkes, J. L., \& Hodges, N. J. (1998). Team sports and the theory of deliberate practice. Journal of Sport and Exercise Psychology, 20(1), 12-34. https://doi.org/10.1123/isep.20.1.12

Kavussanu, M., \& Roberts, G. C. (2001). Moral functioning in sport: An achievement goal perspective. Journal of Sport and Exercise Psychology, 23(1), 37-54. https://doi.org/10.1123/isep.23.1.37

King, L. A., \& Williams, T. A. (1997). Goal orientation and performance in martial arts. Journal of Sport Behavior, 20(4), 397-411.

Lemyre, P. N., Hall, H. K., \& Roberts, G. C. (2008). A social cognitive approach to burnout in elite athletes. Scandinavian Journal of Medicine \& Science in Sports, 18(2), 221-234. https://doi.org/10.1111/i.1600-0838.2007.00671.x

Lochbaum, M., Kallinen, V., \& Konttinen, N. (2017). Task and ego goal orientations across the youth sports experience. Studia sportiva, 11(2), 99-105. https://doi.org/10.5817/StS2017-2-10

Lochbaum, M., Zazo, R., Çetinkalp, K. Z., Wright, T., Graham, K.-A., \& Konttinen, N. (2016). A meta-analytic review of achievement goal orientation correlates in competitive sport: A follow-up to Lochbaum et al. Kinesiology, 48(2), 159-173. https://doi.org/10.26582/k.48.2.15

Mallett, C., Kawabata, M., Newcombe, P., Otero-Forero, A., \& Jackson, S. (2007) Sport motivation scale-6 (SMS-6): A revised six-factor sport motivation scale. Psychology of Sport and Exercise, 8(5), 600-614. https://doi.org/10.1016/i. psychsport.2006.12.005

Mudrak, J., Slepicka, P., \& Slepickova, I. (2018). Sport motivation and dop ing in adolescent athletes. PLOS ONE, 13(10), Article e0205222. https://doi. org/10.1371/journal.pone.0205222

Ntoumanis, N. (2001). Empirical links between achievement goal theory and self-determination theory in sport. Journal of Sports Sciences, 19(6), 397-409. https://doi.org/10.1080/026404101300149357

Palmer, K. K., Chinn, K. M., \& Robinson, L. E. (2017). Using achievement goal theory in motor skill instruction: A systematic review. Sports Medicine, 47(12), 2569-2583. https://doi.org/10.1007/s40279-017-0767-2

Pensgaard, A. M., \& Roberts, G. C. (2002). Elite athletes' experiences of the motivational climate: The coach matters. Scandinavian Journal of Medicine \& Science in Sports, 12(1), 54-59. https://doi.org/10.1034/i.1600-0838.2002.120110.x

Ring, C., \& Kavussanu, M. (2018). The impact of achievement goals on cheating in sport. Psychology of Sport and Exercise, 35, 98-103. https://doi.org/10.1016/i psychsport.2017.11.016

Roberts, G. C., Nerstad, C. G., \& Lemyre, P. N. (2018). Motivation in sport and performance. In O. Brodik (Ed.), Oxford research encyclopedia of psychology (pp. 1-38). Oxford University Press. https://doi.org/10.1093/ acrefore/9780190236557.013.150

Roberts, G. C., Treasure, D. C., \& Balague, G. (1998). Achievement goals in sport: The development and validation of the Perception of Success Questionnaire. Journal of Sports Sciences, 16(4), 337-347. https://doi. org/10.1080/026F40419808559362

Ryan, M. R., \& Deci, L. E. (2000). Intrinsic and extrinsic motivations: Classic definitions and new directions. Contemporary Educational Psychology, 25(1), 54-67. https://doi.org/10.1006/ceps.1999.1020

Sage, L., Kavussanu, M., \& Duda, J. (2006). Goal orientations and moral identity as predictors of prosocial and antisocial functioning in male association football players. Journal of Sports Sciences, 24(5), 455-466. https://doi. org/10.1080/02640410500244531

Standage, M., Duda, J. L., \& Ntoumanis, N. (2003). A model of contextual motivation in physical education: Using constructs from self-determination and achievement goal theories to predict physical activity intentions. Journal of Educational Psychology, 95(1), 97-110. https://doi.org/10.1037/0022-0663.95.1.97 Teixeira, D. S., Pelletier, L. G., Monteiro, D., Rodrigues, F., Moutão, J., Marinho, D. A., \& Cid, L. (2020). Motivational patterns in persistent swimmers: A serial mediation analysis. European Journal of Sport Science, 20(5), 660-669. https:// doi.org/10.1080/17461391.2019.1675768

Tomczak, M., Walczak, M., Kleka, P., Walczak, A., \& Bojkowski, Ł. (2020a). Psychometric properties of the Polish Version of Task and Ego Orientation in Sport Questionnaire (TEOSO). International Journal of Environmental Research and Public Health, 17(10), Article 3593. https://doi.org/10.3390/iierph17103593

Tomczak, M., Walczak, M., Kleka, P., Walczak, A., \& Bojkowski, Ł. (2020b). The measurement of goal orientation in sport: Psychometric properties of the Polish Version of the Perception of Success Questionnaire (POSO). Internationa Journal of Environmental Research and Public Health, 17(18), Article 6641. https://doi.org/10.3390/ijerph17186641

Vallerand, R. J., \& Losier, G. F. (1999). An integrative analysis of intrinsic and extrinsic motivation in sport. Journal of Applied Sport Psychology, 11(1), 142169. https://doi.org/10.1080/10413209908402956

Vallerand, R. J., \& Miquelon, P. (2007). Passion for sport in athletes. In S. Jowette \& D. Lavallée (Eds.), Social psychology in sport (pp. 249-263). Human Kinetics. https://doi.org/10.5040/9781492595878.ch-018

van de Pol, P. K. C., \& Kavussanu, M. (2011). Achievement goals and motivational responses in tennis: Does the context matter? Psychology of Sport and Exercise, 12(2), 176-183. https://doi.org/10.1016/i.psychsport.2010.09.005

van de Pol, P. K. C., \& Kavussanu, M. (2012). Achievement motivation across training and competition in individual and team sports. Sport, Exercise, and Performance Psychology, 1(2), 91-105. https://doi.org/10.1037/a0025967

van de Pol, P. K. C., Kavussanu, M., \& Ring, C. (2012). The effects of training and competition on achievement goals, motivational responses, and performance in a golf-putting task. Journal of Sport and Exercise Psychology, 34(6), 787-807. https://doi.org/10.1123/isep.34.6.787

van Mierlo, H., \& van Hooft, E. A. J. (2020). Team achievement goals and sports team performance. Small Group Research, 51(5), 581-615. https://doi org/10.1177/1046496420913119

Van-Yperen, N. W., \& Duda, J. L. (1999). Goal orientations, beliefs about success, and performance improvement among young elite Dutch soccer players. Scandinavian Journal of Medicine \& Science in Sports, 9(6), 358-364. https://doi. org/10.1111/j.1600-0838.1999.tb00257.x

Vasconcellos, D., Parker, P. D., Hilland, T., Cinelli, R., Owen, K. B., Kapsal, N., Lee, J., Antczak, D., Ntoumanis, N., Ryan, R. M., \& Lonsdale, C. (2020). Selfdetermination theory applied to physical education: A systematic review and meta-analysis. Journal of Educational Psychology, 112(7), 1444-1469. https:// doi.org/10.1037/edu0000420

Waldron, J. J., \& Krane, V. (2005). Whatever it takes: Health compromising behaviors in female athletes. Quest, 57(3), 315-329. https://doi.org/10.1080/00336297. 2005.10491860

Wayment, H. A., \& Walters, A. S. (2017). Goal orientation and well-being in college athletes: The importance of athletic social connectedness. Journal of Sports Sciences, 35(21), 2114-2120. https://doi.org/10.1080/02640414.2016.1257 147

Williams, M. N., Grajales, C. A. G., \& Kurkiewicz, D. (2013). Assumptions of multiple regression: Correcting two misconceptions. Practical Assessment, Research, and Evaluation, 18, Article 11. https://doi.org/10.7275/55hn-wk47

Yukhymenko-Lescroart, M. A. (2018). On identity and sport conduct of studentathletes: Considering athletic and academic contexts. Psychology of Sport and Exercise, 34, 10-19. https://doi.org/10.1016/j.psychsport.2017.09.006 